\title{
UN SISTEMA DE ACULTURACIÓN EN EL MEDITERRÁNEO: LA PRESENCIA DE LA CORONA DE ARAGÓN*
}

Federico Udina Martorell

Fácilmente puede comprenderse, por el anunciado que acabamos de dar, que se trata de abordar el estudio de la expansión mediterránea de la Corona de Aragón desde puntos de vista nuevos. Hasta ahora se ha estudiado el tema desde enfoques muy diversos. Sin duda, se trata de un fenómeno centrífugo de expansíón de la Península hacía afuera, como ha habido otros centrípetos, aunque la Península, como es bien sabido, ha tenido más movimientos hacia el interior que hacia el exterior; recuérdense las invasiones de íberos, de celtas, de los pueblos colonizadores, de los romanos, de los islamitas o de los visigodos.

Ha sido mucho más raro el movimiento centrífugo, y tenemos que remontarnos a épocas muy remotas para encontrar un fenómeno de esta clase; nos referimos, concretamente, a la extensión de la cultura del vaso campaniforme.

* El texto que publicamos es un resumen de la conferencia que, bajo el mismo título, pronunció el profesor Dr. D. Federico Udina Martorell en el marco de este VII Curso de Estudios Medievales. 
También podría traerse a colación, en este sentido, la expansión del islamismo, a través de España, hacia Francia.

Desde otro punto de vista, podríamos decir que en el Mediterráneo se han dado una serie de movimientos que, en cierto modo, seguían los del Sol (más propiamente, los de la Tierra), de Oriente a Occidente y no al revés, como el movimiento que siguieron los pueblos colonizadores. En sentido contrario ha habido las ya citadas expansiones del vaso campaniforme y la mediterránea, de la que hablaremos más extensamente y, finalmente, la del imperio español.

Pero al lado de estas consideraciones, debemos admitir que la expansión mediterránea ha sido estudiada (sobre todo en estos últimos tiempos) como un fenómeno económico; como consecuencia de la formación de un capital comercial, y también, como reacción frente a la piratería. No obstante estas interpretaciones que, como decimos, hoy privan tanto, resultan, como en tantas ocasiones, interpretaciones de la historia demasiado exclusivistas, ya que los fenómenos históricos son más complejos. La vertiente económica no puede despreciarse, como ya apuntó el malogrado profesor Vicens Vives, quien después del Congreso Internacional de Ciencias Históricas de París (1950) aportó los esquemas socio-económicos generales para explicar una serie de fenómenos de la historia de la Corona de Aragón. Y fue él, asimismo, quien indicó la presencia del oro albigense, el comercio de los esclavos, más algún otro elemento que facilitaron lo que podríamos denominar la revolución comercial del siglo xn̂. Pero tampoco puede olvidarse que, junto a todos estos factores, tenemos la presencia de las Cruzadas que, en cierto modo, restablecieron de nuevo la unidad del mundo mediterráneo.

A título solamente indicativo, conviene recordar que los inventos tecnológicos (el arado de rueda, los nuevos arneses del caballo, la rotación trienal del campo, el molino de agua) diexon lugar, también, a una revolución tecnológica y que, sin duda, tuvo gran importancia de cara a la aparición de una mentalidad de ganancia, la cual facilitó, más tarde, la propia expansión mediterránea. Y no puede olvidarse la que podríamos denominar "revolución agrícola» producida en Cataluna como consecuencia de la concentración parcelaria, del incremento de los rendimientos y de la producción de 
plantas especializadas, especialmente la vid; sumando, por tanto, los distintos aspectos que sólo a título indicativo hemos señalado, se produce una primera acumulación del capital y, sobre todo, unos primeros hábitos mentales de inversión (es decir, una mentalidad de lucro, de comercio) que harán posible esa expansión mediterránea.

Debemos mencionar, finalmente, las cuestiones que también planteó ya hace años el profesor Vicens Vives, acerca de la diagonal insular y la ruta de las especias, conceptos que, de ser expuestos, nos llevarían demasiado lejos, teniendo en cuenta, sobre todo, las posiciones iniciales del referido Vicens y las que más tarde han podido elaborar del Treppo, Hillgarth, o Ruiz Doménec. Aún en la misma línea de factores económicos podríamos mencionar la presencia de los judíos y su aportación a todos estos cambios económicos y, en consecuencia, su peso en las futuras empresas de la expansión mediterránea.

Pero al tratar de ésta, no se pueden negligir los fenómenos religiosos, que evidentemente, en una interpretación puramente económica quedan siempre orillados; fenómenos religiosos que podrían ir acompañados de motivaciones de exaltación patriótica, que cuajan en la Reconquista. No hay duda que existen elementos suficientes en la crónica de Jaime I, en la que aparecen muchísimas referencias a motivaciones religiosas, cuya enumeración resultaría prolija, para avalar esta afirmación.

La mentalidad religiosa se acredita más tarde en un documento que Jaime II dirige a Clemente V para demostrar cómo estas motivaciones en la expansión, facilitarían la conquista de los Santos Lugares.

En fin, ante esa diversidad de opiniones, cuya parte de verdad acaso viene encerrada en todas ellas, diriamos con Nicolau d'Olwer, como escribía hace 50 años, que tres fueron los móviles de la expansión mediterránea: uno religioso (deseo de rescatar los Santos Lugares) y en ello juegan un papel importante, naturalmente, las órdenes del Temple y del Hospital; un móvil político (deseo de poder, de dar protección a los cristianos de Egipto y Siria y también de alianzas matrimoniales con las casas reales de Oriente); y un tercer móvil: el lucrativo (deseo de ganancias y de comercio). Y Nicolau d'Olwer terminaba diciendo que en la Edad Media 
realmente todos tenían un poco de pirata, de patriota y de creyente.

Sin embargo, el tema que nos hemos planteado es el de contemplar esta expansión como un fenómeno de aculturación. Entendiendo este término en un sentido muy amplio, indicativo, además, de nuevas vías de investigación.

La aplicación del término aculturación plantea muchos problemas derivados, precisamente, de la misma noción de este término; cuando intentamos definir la aculturación nos movemos en un campo lleno de paradojas e imprecisiones, ya que el término, a pesar de haberse acuñado en 1880 , hace cien años, en la pluma del etnólogo J. W. Powell continúa teniendo, en cierto modo, un sentido vago y general. Luego se adormece en una especie de silencio de maduración, y se halla erráticamente. La noción comenzó a tomar fuerza en América en la literatura etnológica de los difíciles años de la crisis de 1929.

Podríamos decir que el término quiere significar todos los fenómenos de interacción que resultan del contacto de dos culturas. Contacto, que los eruditos ingleses prefieren definir como "culture contact", mientras que en Francia el término no ha tenido un gran éxito, a pesar del uso que de él han hecho etnólogos y antropólogos. Sin embargo, la palabra se ha ido abriendo paso, y su problemática se incluyó entre los grandes temas del Congreso Internacional de Ciencias Históricas de Viena, de 1965: el eminente historiador francés Ferdinand Braudel, profesor del College de France, fue el inspirador de la ponencia que en dicho Congreso presentó el profesor Dupont. El neologismo que nos ocupa (aculturación) - formado a base de dos culturas - contiene toda la fuerza de dicha voz, comprendiendo, a su vez, el concepto de civilización.

Convendría, pues, plantearse qué fenómenos, qué contactos y qué culturas se pueden presentar en el caso que nos ocupa: en el proceso, nada simple, de la expansión mediterránea.

Pero antes de pasar a relacionarlo con nuestro tema, debemos decir que si bien la aculturación se ha aplicado a la etnología, lo cierto es que los estudios de los fenómenos de aculturación pueden orientarse hacia la evolución y cambios 
históricos; las palabras difusión, influencia, imitaciones, modas, son propias de todo proceso de aculturación.

Pero, por otra parte, los fenómenos de esta clase no tienen por qué limitarse a una influencia de la cultura metropolitana sobre la indígena; puede ocurrir lo contrario, es por tanto, un fenómeno de noble polaridad y, en consecuencia, no sólo de una sociedad dominante sobre otra dominada. En otros casos ofrece un aspecto de espontaneidad: la convivencia de gentes, por ejemplo, prudiciéndose de esta manera procesos de integración y de asimilación.

Porque los fenómenos de aculturación, considerados a la vez en sus procesos y en sus resultados, se manifiestan de dos formas: la primera puede ser designada con el término de integración y la segunda con el de asimilación. En el proceso de integración, los elementos extranjeros son incorporados a los sistemas indigenas, que los someten a sus propios esquemas y categorías, pero, a su vez, estos esquemas se integran en el conjunto de la sociedad dominante con modelos y valores autóctonos.

En el otro polo, el proceso de asimilación, realiza el fenómeno a la inversa: la adopción de elementos en el país dominante se acompaña de la eliminación de las tradiciones indigenas, las cuales se ciñen a los modelos de la sociedad dominante.

Téngase en cuenta, no obstante, que entre los dos polos (de integración y asimilación) se sitúa un cierto número de procesos intermedios.

Intentemos ahora examinar algunos aspectos de la expansión mediterránea en relación con los fenómenos de aculturación. En primer lugar conviene dejar a un lado los precedentes de la expansión: nos referimos especialmente a la flota que el Conde Suñer de Empuries había armado para luchar contra los corsarios y los musulmanes, así como, más tarde, las relaciones de los condes de Barcelona con Sicilia, a través del enlace del conde Ramón Berenguer II con Mafalda, incluso el intento de Ramón Berenguer III, en compañía de los pisanos, de conquistar Mallorca, hasta el momento culminante en que Cataluña, a base del soporte continental que cosechó al unirse con Aragón, llega a los primeros jalones de Jaime I el Conquistador. 
Porque, a partir del siglo XIII, se comienzan a hallar claros fenómenos de aculturación en la reconquista de Mallorca y Valencia. Si hablamos de reconquista, permítasenos una digresión con respecto a esta palabra, puesto que entendemos que tanto la conquista de Mallorca como la de Valencia deben circumscribirse a fenómenos de Reconquista; o sea, reconquista con un contenido religioso.

Con respecto a Mallorca, no hay duda que se produce un claro fenómeno de aculturación, toda vez que la Mallorca musulmana se interrumpe y nace una Mallorca cristiana: se produce un corte y así lo proclama, por ejemplo, el repartimiento que Jaime I hace en la isla; hay un verdadero cambio con respecto al régimen de propiedad, hay una expulsión de la población y una afluencia de gentes nuevas, una implantación del régimen feudal catalán; la extensión de una nueva lengua, la introducción de una nueva religión y, por tanto, se producen de manera clara fenómenos de aculturación, unas veces por asimilación y otras veces por integración.

En Valencia, el fenómeno adquiere unos matices algo distintos: en primer lugar, la campaña de Valencia dura unos doce años, existe una gran densidad de población musulmana y son pocos los colonos cristianos que van a poblar de momento el territorio recién reconquistado, ya que prefieren situarse en lugares estratégicos; los conquistadores organizan los territorios de forma menos intensa, pues evidentemente se persigue establecer una organización con aspecto claramente musulmán. Aquí se produce una impresión de continuidad, sobre todo en el campo; la moneda, el calendario, las edificaciones, las costumbres se introducen muy poco a poco, incluso en cuanto a edificaciones, las iglesias góticas, no se levantan en seguida. El padre Burns al hablar de la transformación de Valencia y de la intención del monarca de que tenga una ordenada transición, lenta y despaciosa, nos dice lo siguiente: "las presiones hacia una aculturación eran inexorables, pero el telón de fondo geográfico de la existencia cotidiana del musulmán prestaba confort y fuerza; había lugares y momentos en los cuales debió parecer como que nada había cambiado, pero en el curso del siglo XIII la sociedad islámica y las estructuras del reino valenciano, organizadas por Jaime I, cambiaron". 
Con todo ello, podríamos decir que el fenómeno de aculturación por asimilación, al terminar el siglo XIII, ha sido casi total.

Entre las instituciones hay una que se impone en los dos reinos: se trata de la monarquía, con la característica típica de unión personal, que se introduce en ambos territorios; es la misma política que encontraremos en Cerdeña, en Sicilia y en Nápoles, aunque en aquella isla de manera diferente.

Desde el punto de vista demográfico, los fenómenos de aculturación pueden estudiarse sobre los repartimientos, más en el reino de Mallorca que en el de Valencia.

Por otra parte, la promulgación de fueros y leyes marítimas son otros tantos fenómenos de aculturación que catalano-aragoneses realizaron en Valencia. En otro orden de cosas, debemos registrar los fenómenos religiosos: por una parte, las conversiones y, por otra, la influencia del islamismo sobre el cristianismo, y al revés, con fenómenos de integración en las construcciones de iglesias. Una introducción clarísima en el campo religioso es el culto de Santa María, sumamente enraizado en la Crónica de Jaime I, y llevado a las escasísimas comunidades mozárabes. Sin embargo, véase que en todo ello no hacemos más que apuntar caminos de investigación y posibles hipótesis de trabajo sobre la problemática de la aculturación.

El caso de Sicilia es muy distinto del de la reconquista de Mallorca y Valencia; sin embargo, la monarquía de unión personal, fenómeno indudable de aculturación, se extiende a todos los rincones del dominio mediterráneo de la Corona de Aragón; asimismo, se abre un nuevo camino para las Cortes, que aparecen como un fenómeno de aculturación dentro de las instituciones que ya existen. Ambos temas, el de la monarquía y el de las Cortes han sido, desde otros puntos de vista, muy estudiados, pero aparecen bajo nueva luz al tratarlos desde el punto de vista de la aculturación. Ya escribíamos en 1973, en el IX Congreso de Historia de la Corona de Aragón, al explicar una ponencia sobre: "La organización política y administrativa de la Corona de Aragón de 1416 a 1516 " que no era necesario "insistir en este tema en cuanto a los reinos peninsulares»; en cuanto a los extra-peninsulares, por haber sido la cuestión de la unión 
personal objeto de viva controversia, conviene recoger algunos datos.

Efectivamente, Camilo Giardina en su interesante artículo: "Unione personale e reale fra Sicilia e Aragona", se expresa claramente con respecto a este problema al afirmar textualmente: "los reyes de Aragón consideraron siempre sus dominios, reinos, condados, ducados, como entidades distintas, unidas solamente con vínculos personales a la Corona aragonesa. Ninguno de sus estados, comprendidos los reinos de Sicilia y de Nápoles, perdió nunca su propia autonomía nacional y jurídica y el uso del propio derecho; todo dominio consideró válidas únicamente las propias leyes y nunca concedió ningún valor jurídico a las leyes de los estados dominantes: Aragón o Cataluña: Ya lo afirmaba hace más de treinta años el ilustre profesor español Beneyto Pérez, quien decía que la adquisición de diversos territorios por la corona aragonesa nunca abolió ni sustituyó la legislación particular de cada uno de los estados».

Interesante camino de investigación ofrece el estudio de las Cortes desde el punto de vista de la aculturación en un fenómeno de sincretismo: el parlamento ya existe desde época normanda en Sicilia y la aportación catalano-aragonesa respecto a esta institución se establece a través de la llamada "communicatio". "Come il sistema delle autonomie integralmente applicato face rimanere salvo l'organismo di regni domini uniti tra loro nella persona del comune sovrano, cioè, salve loro prerogative nazionali, cosi fece rimanere intatta la pienezza della loro autonomia legislativa, nel senso che erano leggi soltanto quelle che erano state espressamente promulgate del sovrano per ciascuno di essi. Alla luce di questa osservazioni, lo stesso istituto della communicatio..."

Con respecto a Cerdeña debemos subrayar un hecho muy importante, y es que mientras Sicilia era reino, Cerdeña no lo era; bajo pisanos y genoveses y también bajo la dominación musulmana se establecieron en Cerdeña, como se sabe, cuatro judicaturas: Arborea, Cagliari, Torres y Gallura. Cuando Jaime II y los monarcas sucesivos constituyeron el reino, bajo la unión personal, continuó esta división como organización oficial y territorial.

Desde un punto de vista económico no puede olvidarse que Cerdeña, bajo las dominaciones anteriores a la Corona 
de Aragón, es decir, bajo los pisanos y genoveses, tuvo una economía agrícola y ganadera, articulada de cara a una gran posibilidad de exportación, pero ahora, bajo la dominación catalano-aragonesa, el tráfico comercial, interferido por la ocupación catalana, dirigió sus producciones hacia otros mercados. Recuérdese que Cerdeña fue víctima de una verdadera ocupación militar con la consiguiente feudalización de toda la isla, produciéndose nuevos fenómenos de aculturación, cuyas consecuencias, como ha escrito Hillgarth, tendrian efectos residuales hasta el siglo XIX.

Pero ya que hablamos de Cerdeña no debemos olvidar que, desde un punto de vista demográfico, se producen hechos como la drástica disminución de población autóctona, caída, en gran parte, en la esclavitud; y fenómenos de repoblación en Sásser, por ejemplo, y en Alguer, o lingüísticos, cuyas reliquias aún se pueden estudiar en esta última, todo ello objeto de nuestro estudio como fenómenos típicos de aculturación.

En otro ángulo geográfico de la Corona de Aragón, en los territorios peninsulares, queremos consignar que se ofrecen también caminos nuevos de investigación y de hipótesis de trabajo con respecto a la aculturación, cuando se produce la entronización de la dinastía de Trastámara, puesto que ésta, como ya recogió con su perspicacia Vicens Vives, se adaptó en seguida en su segundo representante a la nueva mentalidad. "Una brillante comitiva a fines de junio de 1412 , en la que figuraban nobles, abades, mercaderes y cronistas, desplegando la magnificencia y el lujo de la aristocracia castellana, acompañó a su nuevo reino a la familia de don Fernando, en cuyo primer plano descollaba el primogénito Alfonso: fue él quizá quién más sufrió el choque del momento, pues no sólo cruzaba la frontera territorial, sinó la línea psicológica: del lado de acá, el ambiente de la infancia; al otro lado, un mundo en que muchas de las cosas debían hacerse y pensarse diferentemente."

Finalmente, y volviendo a los dominios mediterráneos, bien conocidos son los fenómenos de las modas y costumbre catalano-aragonesas en los territorios isleños mediterráneos, sobre todo en Nápoles, a partir de Alfonso el Magnánimo, los cuales serán desarrollados durante los si- 
glos XVI y XVII, en especial bajo el virreinato del Duque de Maqueda.

Muchas otras vías de investigación y de búsqueda podrían aún señalarse con respecto al fenómeno que nos ocupa, pero creemos que para una conferencia en que se han pretendido señalar nuevos rumbos de investigación, es suficiente.

Sin embargo, no querríamos dejar de aludir a una figura literaria que nos serviría de colofón: la que nos ofrece el Cronista Desclot cuando trata de la influencia de la Corona de Aragón en el Mediterráneo, señalando que esta fue tan intensa, que incluso los peces que corrían por los mares debían llevar en su cola las cuatro barras de Aragón. 